\title{
Heart failure monitoring with a cardiac resynchronization therapy device-based cardiac contractility sensor: a case series
}

\author{
Jacques Mansourati ${ }^{1,2^{*}}$, Mélanie Heurteau ${ }^{3}$ and Jérôme Abaléa ${ }^{1}$
}

\begin{abstract}
Introduction: The SonR signal has been shown to reflect cardiac contractility. It is recorded with an atrial lead connected to a cardiac resynchronization therapy defibrillator. For the first time, clinical evidence on the use of the SonR signal in the monitoring of the clinical status of heart failure patients implanted with cardiac resynchronization therapy defibrillator are presented through three clinical cases.

Case presentation: In the two first patients (non-Hispanic/Latino white), the SonR amplitude increases concomitantly to clinical status improvement subsequent to cardiac resynchronization therapy defibrillator implantation. In the third patient (non-Hispanic/Latino white), a decrease in SonR amplitude is observed concomitantly to atrial fibrillation and clinical status deterioration.

Conclusions: This case series reports the association between SonR signal amplitude changes and patients' clinical status. Combined with remote monitoring, early SonR signal amplitude remote monitoring could be a promising tool for heart failure patients' management.
\end{abstract}

Keywords: Heart failure, Monitoring, Cardiac resynchronization therapy, Peak endocardial acceleration, SonR, Sensor

\section{Introduction}

The peak endocardial acceleration signal, or SonR signal has been shown to correlate with the first heart sound [1], supporting the hypothesis that the SonR signal amplitude correlates with left ventricular $(\mathrm{LV}) \mathrm{dP} / \mathrm{dt}_{\max }$, a measure of the contractile function of the heart [2-5] and may be a useful tool to monitor cardiac function. In order to further assess this hypothesis, we evaluated the association between SonR signal amplitude and patients' clinical status through the three following case reports.

The hemodynamic SonR sensor (SonR $R^{\mathrm{m}}$ sensor, Sorin CRM, Clamart, France) is a micro-accelerometer encapsulated in a hermetic can inside the tip of an atrial pacing lead (SonR ${ }^{\mathrm{m}}$ sensor, Sorin CRM, Clamart, France). The SonR signal is monitored and computerized by the embedded SonR algorithm through an implantable system

\footnotetext{
* Correspondence: jacques.mansourati@chu-brest.fr

'Department of Cardiology, University Hospital of Brest, Hôpital de la Cavale Blanche, Boulevard Tanguy Prigent, 29609 Brest, France

'EA 4324, ORPHY, Université de Bretagne Occidentale, 3 Rue des Archives, 29238 Brest, France

Full list of author information is available at the end of the article
}

consisting of an atrial pacing lead (SonRTip ${ }^{\mathrm{Tm}}$ lead, Sorin CRM, Clamart, France) connected to a cardiac resynchronization therapy defibrillator (CRT-D) device. Additionally, SonR allows automatic weekly atrioventricular (AV) and interventricular (VV) delays optimization in heart failure (HF) CRT-D patients, at rest and exercise [6-9].

The three following clinical cases report information on recipients of Paradym $\mathrm{RF}^{\text {Tu }}$ SonR CRT-D (Sorin CRM SAS, Clamart, France), implanted for HF with either ischemic (ICM) or dilated cardiomyopathy (DCM).

\section{Case presentation}

The first patient is a 70-year-old man (non-Hispanic/ Latino white) with an ICM. Two myocardial infarctions occurred in 1986 and 1997, followed by a coronary artery bypass grafting (CABG) in 1997. He was resuscitated from a cardiac arrest related to graft occlusion in 2003. A first single-chamber implantable cardioverter-defibrillator (ICD) was implanted in 2006 (MADIT II indication). In 2012, the patient became severely symptomatic (New-York Heart Association (NYHA) class III) with a left bundle branch block (LBBB) and a left ventricular ejection fraction (LVEF)

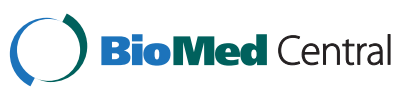




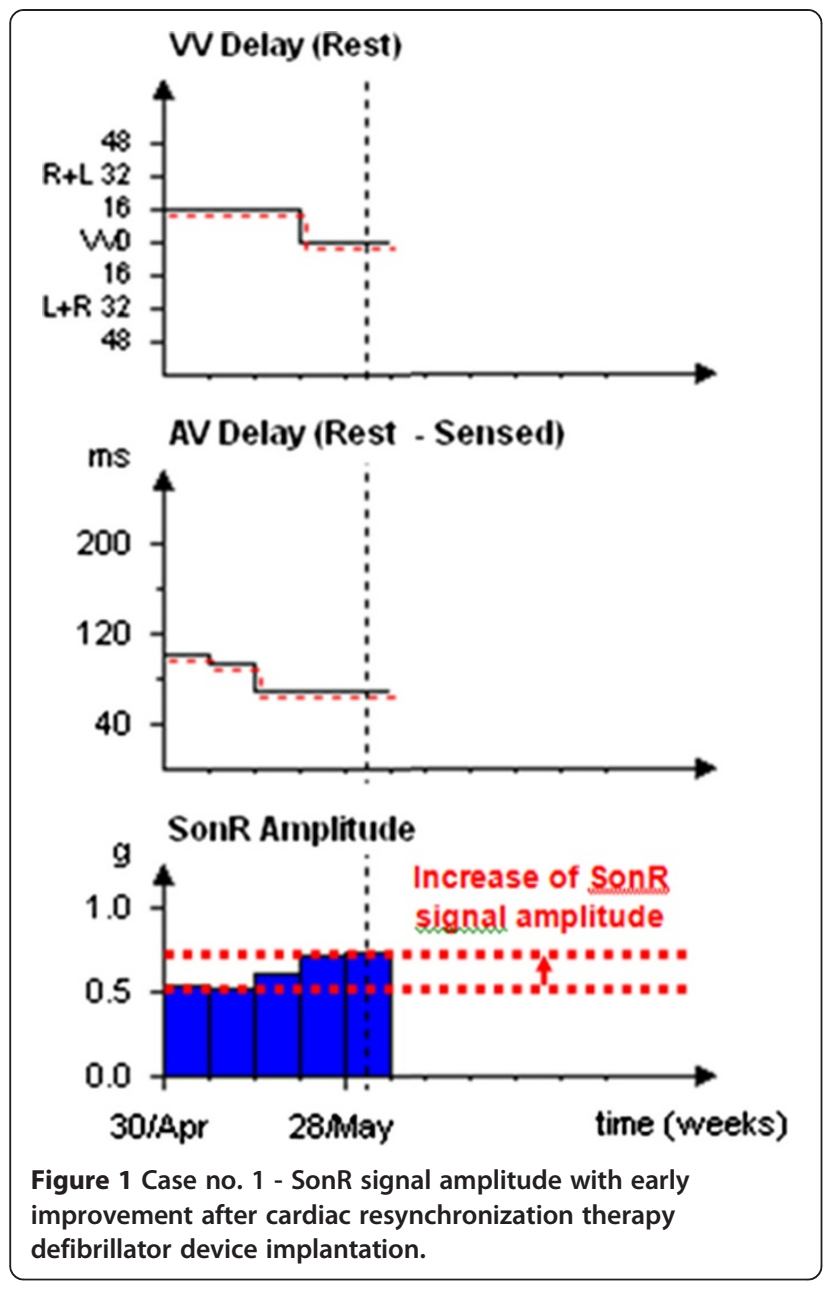

of $26 \%$. Therefore, the single chamber ICD was upgraded to the CRT-D device. Within three weeks, the AV and VV delays were automatically adjusted by the device on a weekly basis; the patient became asymptomatic while the SonR signal amplitude increased (Figure 1). No concomitant therapy changes occurred during this period.
The second patient is a 65-year-old woman (nonHispanic/Latino white) who presented with a DCM related to radiotherapy and chemotherapy (left-side breast cancer treated in 2007). She was in NYHA class II/III, with a LVEF of $35 \%$ and a LBBB. The patient was implanted with the CRT-D device from the right thoracic side in November 2011. However, the first attempt of LV lead implantation was unsuccessful and ventricular pacing was prevented until the second attempt, which succeeded in February 2012. Subsequently, the patient progressively improved (NYHA class I on September 2012). Figure 2 shows the SonR signal amplitude evolution during these two periods (before and after LV lead implantation): the amplitude increased while the patient's status improved after the successful LV lead implantation.

A third 74-year-old man (non-Hispanic/Latino white) underwent CABG in 1993. In 2005, he experienced atrial fibrillation (AF) which resulted in HF. After treatment with amiodarone, sinus rhythm (SR) was restored and the patient became asymptomatic with a LVEF of $12 \%$ and LBBB. In 2005, the patient was implanted with a prophylactic single chamber ICD. In 2012, the patient became severely symptomatic (NYHA class III) with LBBB and a LVEF of 20\%. Based on this evolution, the patient was upgraded with the CRT-D device, in May. During an outpatient visit on July 17, an electrocardiogram (ECG) revealed AF. The device diagnosis showed that AF started on July 16 with a mode switch to VVI $80 \mathrm{bpm}$. Both ventricles were only captured $90 \%$ of the time. On July 26 , the patient was hospitalized for HF and his HF treatment was modified. On September 9, the patient was in NYHA class I and his SR was restored by electrical cardioversion on October 10. No therapy changes occurred during this period. Figure 3 shows the decrease of the SonR signal amplitude that started concomitantly to AF and remained low as long as AF lasted. Following sinus rhythm restoration on October 10, the SonR signal amplitude started to increase,

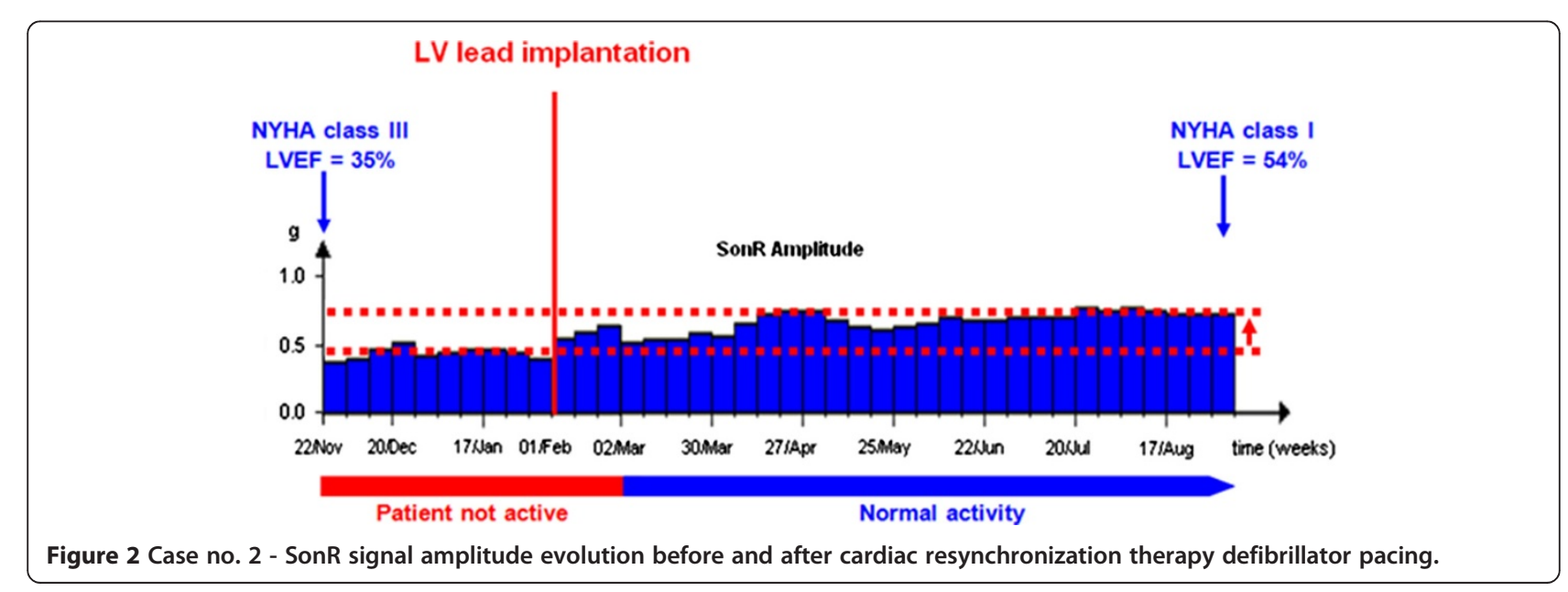




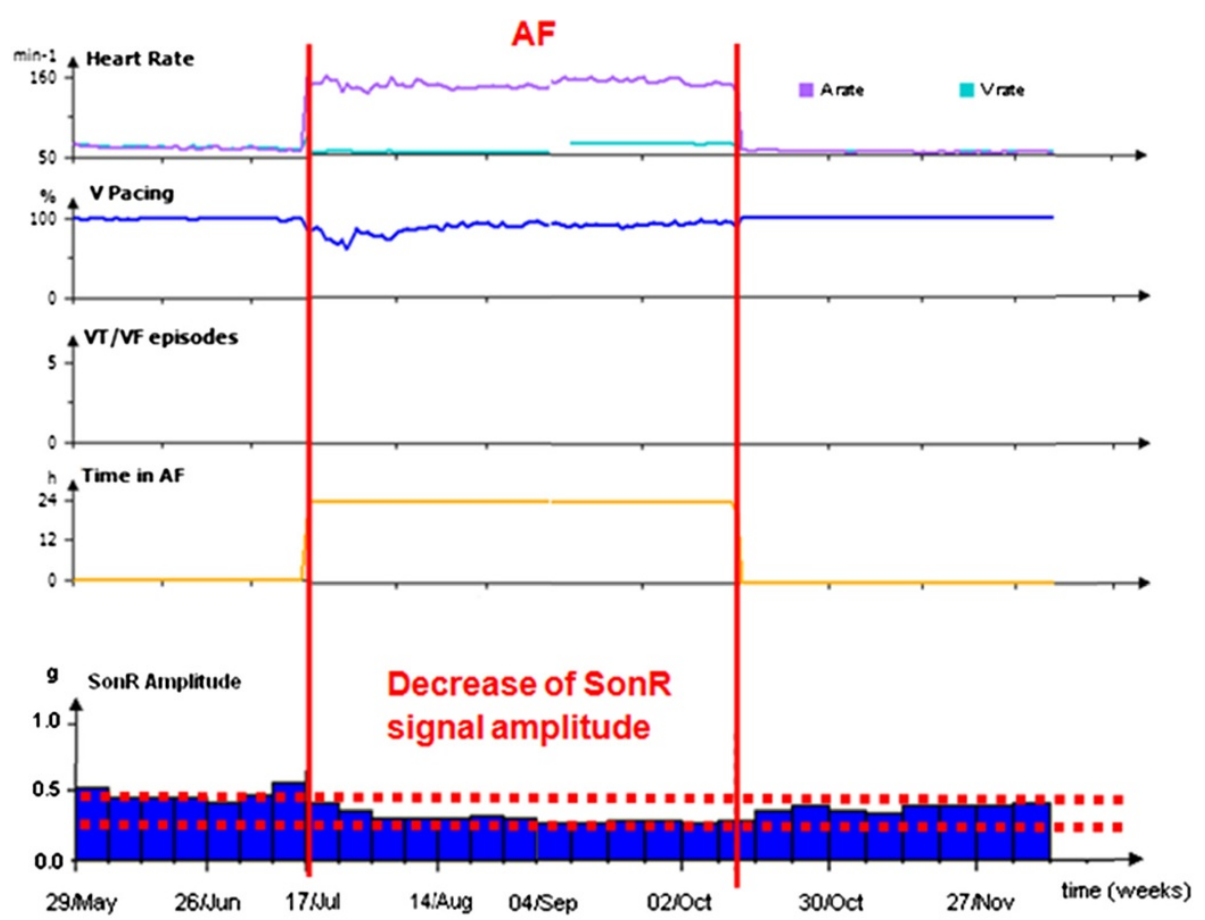

Figure 3 Case no. 3 - SonR signal amplitude evolution in the presence of atrial fibrillation and partial loss of biventricular capture.

reaching its initial value after the persistence of the sinus rhythm.

Therefore, an association between the SonR signal amplitude change and patients' clinical status based on NYHA was observed in these three clinical cases.

\section{Discussion}

This report is the first to describe SonR signal amplitude changes according to patients' clinical status. In the two first patients, the SonR amplitude increases concomitantly to clinical status improvement after CRT-D implantation. In the third patient, a decrease in SonR amplitude is observed concomitantly to an atrial fibrillation episode and clinical status deterioration.

Further adjustments to the SonR device could be of benefit to the monitoring process of CRT-D patients: (1) while AV and VV delays optimization are automatically performed weekly by SonR, displaying daily SonR amplitude values would be preferable for monitoring purposes; (2) finally, the percentage of modification in clinical status could be quantified for the development of an alert.

Combined with remote monitoring, which is now widely accepted based on accumulating evidence that outcomes are better compared with standard in-clinic follow-up, early SonR signal amplitude remote monitoring could be a promising tool for HF patients' management. Several recent trials on HF monitoring based on device diagnostic information confirmed the difficulty to monitor HF using a sole indicator and suggested the need to incorporate multiple parameters [10]. In this context, the SonR signal amplitude could be combined with other device-based parameters in order to improve the accuracy of the diagnostic. However, technical improvements and outcome prospective trials are warranted.

\section{Consent}

Written informed consent was obtained from the patients for publication of this case series and any accompanying images. A copy of the written consents is available for review by the Editor-in-Chief of this journal.

\section{Abbreviations}

AF: atrial fibrillation; AV: atrioventricular; CABG: coronary artery bypass grafting; CRT-D: cardiac resynchronization therapy defibrillator; DCM: dilated cardiomyopathy; HF: heart failure; ICD: implantable cardioverter-defibrillator; ICM: ischemic cardiomyopathy; LBBB: left bundle branch block; LVEF: left ventricular ejection fraction; NYHA: New York Heart Association; SR: sinus rhythm; W: interventricular.

\section{Competing interests}

Jacques Mansourati declares consultant fees and research fees with Biotronik, Boston Scientific, Medtronic, St Jude Medical and SORIN Group. Melanie Heurteau is employed by Sorin Group. Jerome Abalea declares no competing interests.

\section{Authors' contributions}

$J \mathrm{M}$ and $\mathrm{JA}$ analyzed and interpreted the patient data regarding the heart failure disease and the signal analysis. All authors read and approved the final manuscript.

\section{Acknowledgements}

We thank Frédérique Maneval and Anne Rousseau-Plasse who provided editorial assistance on behalf of Sorin CRM SAS. 


\section{Author details}

'Department of Cardiology, University Hospital of Brest, Hôpital de la Cavale Blanche, Boulevard Tanguy Prigent, 29609 Brest, France. 'EA 4324, ORPHY, Université de Bretagne Occidentale, 3 Rue des Archives, 29238 Brest, France.

${ }^{3}$ Sorin CRM SAS, Avenue Réaumur, 92140 Clamart, France.

Received: 1 July 2013 Accepted: 20 November 2013

Published: 27 January 2014

\section{References}

1. Tassin A, Kobeissi A, Vitali L, Rouleau F, Ritter P, Gaggini G, Dupuis JM: Relationship between amplitude and timing of heart sounds and endocardial acceleration. Pacing Clin Electrophysiol 2009, Suppl 1:101-104.

2. Bongiorni MG, Soldati E, Arena G, Quirino G, Vernazza F, Bernasconi A Garberoglio B: Is local myocardial contractility related to endocardial acceleration signals detected by a transvenous pacing lead? Pacing Clin Electrophysiol 1996, 19:1682-1688.

3. Rickards AF, Bombardini T, Corbucci G, Plicchi G: An implantable intracardiac accelerometer for monitoring myocardial contractility. The Multicenter PEA Study Group. Pacing Clin Electrophysiol 1996 19:2066-2071.

4. Bordachar $P$, Labrousse $L$, Ploux $S$, Thambo JB, Lafitte $S$, Reant $P$, Jais $P$, Haissaguerre M, Clementy J, Dos Santos P: Validation of a new noninvasive device for the monitoring of peak endocardial acceleration in pigs: implications for optimization of pacing site and configuration. J Cardiovasc Electrophysiol 2008, 19:725-729.

5. Bordachar P, Garrigue S, Ritter P, Ploux S, Labrousse L, Casset C, Haissaguerre M, Dos Santos P: Contributions of a hemodynamic sensor embedded in an atrial lead in a porcine model. J Cardiovasc Electrophysiol 2011, 5:579-583.

6. Padeletti $L$, Porciani MC, Ritter $P$, Michelucci A, Colella A, Pieragnoli $P$, Costoli A, Ciapetti C, Sabini A, Demarchi G, Gillio-Meina L, Gaggini G, Gensini GF: Atrioventricular interval optimization in the right atrial appendage and interatrial septum pacing: a comparison between echo and peak endocardial acceleration measurements. Pacing Clin Electrophysiol 2000 23:1618-1622

7. Leung SK, Lau CP, Lam CT, Ho S, Tse HF, Yu CM, Lee K, Tang MO, To KM, Renesto F: Automatic optimization of resting and exercise atrioventricular interval using a peak endocardial acceleration sensor: validation with Doppler echocardiography and direct cardiac output measurements. Pacing Clin Electrophysiol 2000, 23:1762-1766.

8. Dupuis JM, Kobeissi A, Vitali L, Gaggini G, Merheb M, Rouleau F, Leftheriotis $G$, Ritter $P$, Victor J: Programming optimal atrioventricular delay in dual chamber pacing using peak endocardial acceleration: comparison with a standard echocardiographic procedure. Pacing Clin Electrophysiol 2003, 26:210-213.

9. Delnoy PP, Marcelli E, Oudeluttikhuis H, Nicastia D, Renesto F, Cercenelli L, Plicchi G: Validation of a peak endocardial acceleration-based algorithm to optimize cardiac resynchronization: early clinical results. Europace 2008, 10:801-808.

10. Cowie MR, Sarkar S, Koehler J, Whellan DJ, Crossley GH, Tang WHW, Abraham WT, Sharma V, Santini M: Development and validation of an integrated diagnostic algorithm derived from parameters monitored in implantable devices for identifying patients at risk for heart failure hospitalization in an ambulatory setting. Eur Heart J 2013, 34:2472-2480.

doi:10.1186/1752-1947-8-27

Cite this article as: Mansourati et al.: Heart failure monitoring with a cardiac resynchronization therapy device-based cardiac contractility sensor: a case series. Journal of Medical Case Reports 2014 8:27.

\section{Submit your next manuscript to BioMed Central and take full advantage of:}

- Convenient online submission

- Thorough peer review

- No space constraints or color figure charges

- Immediate publication on acceptance

- Inclusion in PubMed, CAS, Scopus and Google Scholar

- Research which is freely available for redistribution

Submit your manuscript at www.biomedcentral.com/submit
Ciomed Central 